\title{
Ways of modernization of informational training for university students
}

\author{
N. A. Fomina*, D. S. Ivanova, M.V. Somova, and $O$. $V$. Knyazkova \\ FSBEI HE “Ryazan State University named after S.A. Yesenin", 390000, Ryazan, Russia
}

\begin{abstract}
The article substantiates the need for informatization of education in general, and higher professional education in particular, requiring the modernization of forms, methods and content of information training of students in the light of the implementation of the program "Digital Economy of the Russian Federation". The article presents the ways of improving the informational training of university students. The research methods are as follows: analysis of literature, documents, and electronic resources; observation, questioning of participants in the educational process, methods of mathematical statistics. The analysis shows that the project-based method of training, monitoring and control of the content of electronic resources, the integrated use of distant learning systems, online software for collaborative work, the implementation of artificial intelligence technology in education will allow to form the media literacy of future specialists that meets the modern requirements of the economy and society.

The study was conducted on the basis of S.A.Yesenin Ryazan State University in various areas and profiles of education. One of the types of project activities based on modern digital technologies is a hackathon. The goal of such a project is to develop and create a media product in a given professional field. This can be a website, an application, or an interactive software. A team of students is working on a socially significant task. Preparing students for the project-based work by using modern digital technologies has shown its effectiveness for being included in the "Startup as a Degree" Program. The final qualification work prepared in this format may represent a project that is in demand in the field of professional activity. The experimental work of the study was carried out by dividing students into a control group and an experimental group. The range, difference, and significance of changes in the level of informational training in the control and experimental groups were evaluated by the Fischer - Yates criterion. The analysis of individual and collective projects developed by the students, the qualitative analysis of the students' answers from the both groups to the questions of questionnaires and tests showed that the students of the experimental group revealed a higher level of readiness for professional activity, self-study, self-education, which indicates the effectiveness of the proposed approach.
\end{abstract}

\footnotetext{
*Corresponding author: pslfom@mail.ru
} 


\section{Introduction}

The Decree of the President of the Russian Federation 'On National Goals and Strategic Objectives of the Development of the Russian Federation for the Period of up to 2024" specifies the tasks of the education system and its priorities which implies the formation of a modern infrastructure of general education.

Nowadays the conditions of global digitalization of the economy, technological changes, and the development of distant technologies determine new methodological aspects of informatization of higher education. We observe the rapid change in the forms, methods and the content of informational training of university students. Education has entered the stage of digital transformation and required a timely response from all its participants. In accordance with the new reality, informational training of students requires application of a new technological and methodological research, strengthening the role of science, and the timely replacement of the outdated standards.

Our research was based on the analysis of theoretical and practical works that reveal the peculiarities of the organization of the educational process as a whole (based on the theory of activity, we considered the main structural elements and such aspects of the cognitive activity of students as perception, comprehension and practical application (Babansky Yu.K., 1988 ); assessed its success by the end result, and not only by synopses, abstracts, projects as a means of assimilating educational material (Bespalko V.P., 1998); aspects of the development of informatization of education, various information technologies, the essence and possibilities of distance education (Robert I. V., 2008; Polat E.S., 2005), including the possibility of distance learning in force majeure (Karkhanyan G.G. [1]); the current state of digital education and ways of its modernization (Gunko T. and Smale V. [2], Ferley E., Musselin K., Andresan I., Ivanova Z.I., Danilina N.V., Slepnev M.A. [3,4], Grek S. [6], Gurova G . [6]); eg analysis of the content of electronic resources of the educational process (Vlasova T.I. [7], Shagdarova T.V. [8]); the possibilities of projectbased learning in higher education as a direction for the development of professional competencies of students and the possibility of implementing student-centered learning (Go P., Saab N., Post L.S. [9], Yakovleva O.V. [10]).

Over the last few years, interest in distant learning has grown rapidly. Of course, this is due to the need for restrictive measures taken in an unstable situation concerning the infectious diseases. However, the introduction of such measures is not the main reason for the development of distant learning at the university. Informatization of society and education, expansion of the opportunities of modern information technologies, transition to the digital economy, and the development of the Russian software market actualize the innovation in the forms and methods of teaching. The factors such as electronic work with documents, reduction of the amount of routine work, opportunity to improve their professional level on-the-job, to obtain a second education, additional and extramural education, make the process of wide introduction of digital technologies in the educational process extremely necessary. Evaluation of opportunities of distant learning in force majeure conditions is given in the works of G.G. Karkhanyan. The current state of digital education on the ways of its modernization is considered in the works of Gunko, T. and Smale, V., Furlie, E., Musselin, Christine and Andresani, Z.I. Ivanova, N.V. Danilina, M.A. Slepnev. The ways for analysis of the content of electronic resources in the educational process are shown by T.I. Vlasova. The overview of opportunities of project-based learning in higher education is given in the works of Go P., Saab N., Post L.S.

The goals and objectives of our research are as follows: to develop the ways for modernization of informational training of university students in the light of the 'Digitalization of the Economy of the Russian Federation Program', to practically evaluate the proposed approach, to test the effectiveness of the selected ways. 
The hypothesis of the proposed study: the project-based method of teaching, monitoring and control of the content of electronic resources, the integrated use of distant learning systems, online software for collaborative work, the application of artificial intelligence technology in education will allow to form the media literacy of future specialists that meets the modern requirements of the economy and society.

\section{Materials and Methods}

The research was conducted at the S.A. Yesenin Ryazan State University in various areas and profiles of education: the Faculty of Physics and Mathematics, the Institute of Pedagogy, Psychology and Social Work, the Faculty of the Russian Philology and National Culture. It was attended by 612 students $1-3$ courses aged 18 to 23 years.

At the same time, 300 students made up a control group, 312 - an experimental one.

The research methods: theoretical analysis of pedagogical and methodological literature, documents and materials of periodicals, electronic resources, observation, questioning of participants of the educational process, methods of mathematical statistics.

In addition, the method of observing students of both groups was used in order to determine their level of their cognitive interest in educational and extracurricular activities based on modern digital technologies.

Testing of students of the control and experimental groups was carried out according to the method of Bespalko V.P. He allowed to diagnose the level of their informational training in accordance with the standards of the curriculum of the disciplines of the course "Informatics".

Methods of mathematical statistics were used to process the obtained empirical data: descriptive statistics, methods of Kolmogorov - Smirnov, Wilcoxon, McNamara, Fisher Yeethis.

The research included several stages.

At the first, ascertaining, stage, the level of training in the field of information activity and information interaction among students of the control and experimental groups was determined.

At the second, forming, stage, the directions of modernization of their information training on the basis of modern digital technologies were determined and tested. Students of the experimental group took part in the approbation.

At the last, control, stage, the effectiveness of the work carried out by us with the students of the experimental group on the development of their information training was determined.

\section{Results}

The analysis of the results of the ascertaining experiment showed the initial level of training in the field of information activity and information interaction among students of the control and experimental groups.

During the experimental work, there was analyzed the initial level of informational training of students. The evaluation of the results of the tasks performed by the students was carried out according to the method proposed by V.P. Bespalko based on the calculation of the coefficient $\mathrm{k}=\mathrm{m} / \mathrm{n}$, where $\mathrm{n}$ - the number of correct answers, $\mathrm{m}$ - the total number of questions. After that, the test results were divided into three levels of informational literacy. The first level is adaptive. The coefficient of this level varies from 0 to 0.3 points. The second level is presentational. The coefficient is respectively in the range 
from 0.4 to 0.7 points. The third level, which interval is from 0.8 to 1 , is considered as integrative.

As can be seen from Table 1, more than half of the students in the groups had the 1st adaptive, that is, a low level of readiness for professional activity based on information technologies. They were able to reproduce the assignments and examples of the use of information technology suggested by the teacher.

Only one fifth of them had a presentation level. These students have modified the suggested examples for more complex ones.

And only a tenth of the students demonstrated an integrative level, manifested in a variable form of educational activity, in which they created electronic resources not only on the basis of the analyzed examples, but also independently created scripts, guided by the choice of basic and additional software when executing projects, could fully develop as the software product itself and the methodology for its application.

Table 1. The initial level of information training among students of the experimental and control groups

\begin{tabular}{|c|c|c|}
\hline Level & \multicolumn{2}{|c|}{ Number of students (in\%) } \\
\hline & Experimental group & Control groups \\
\hline Adaptive & 70 & 68 \\
\hline Presentational & 20 & 21 \\
\hline Integrative & 10 & 11 \\
\hline
\end{tabular}

These data were also confirmed by the results of observation of students in the process of their educational activities.

Taking into account these results of empirical research, we have identified and tested the directions of work to modernize their information training based on modern digital technologies.

The project-based methods of work relying on modern digital technologies is chosen as the basis for the modernization of informational training of students. The project-based methods of work is not a fundamentally new form of educational activity. However, with the rapid development of the information society, as well as with the informatization of education and other areas of economy, this approach takes on a new specifity.

In the course of work, the students get acquainted with the modern opportunities of information technologies, which have entered into almost all spheres of professional activity of a person. At the heart of each project there is a problem, the search for solutions to which is the task of the students. Since no problem can practically affect only one subject area, there is a need for joint collective work of specialists in various fields of training, which leads to formation of inter-subject relations, and actualization of the need for building up competence in various academic disciplines.

The process of collaborative work, analysis of existing approaches to solving the project problem, and finding the author's own solution requires skills, abilities and knowledge in the field of modern information technologies. The project-based methods of work in the process of informational training begins in the first year when studying the discipline "Information and Communication Technologies and Media Information Literacy". The topics of the projects are related to the specialty of the student training and allow students to form a cognitive interest in both the disciplines of the professional cycle and the disciplines of the Informatics cycle.

The further work on the basis of modern digital technologies is conducted not only within the framework of one discipline or subject. The students develop and implement projects in the course of educational, scientific, and research work. The theme can be defined within the framework of the academic discipline, the additional scientific research, 
as well as within the educational work of the university. The students take an active part in the project activities of the city and the region.

One of the types of project activities based on modern digital technologies is a hackathon. The goal of such a project is to develop and create a media product in a given professional field. This can be a website, an application, or interactive software. A team of students works at a socially significant task. The students of the Physics and Mathematics department are responsible for the technical side whereas the students of other areas develop the content. The students' research works are carried out individually or collectively both in the course of educational activities and in the social activities of the university or the region. For example, a project devoted to the linguistic analysis of the text is considered in the work of Ivanova D.S. [11].

The process of student preparation for the project-based work by using modern digital technologies has shown its effectiveness in the involvement of the university in the program of the Russian Federation "Startup as a Degree". The final qualification work performed in this format is a business project, which, as a rule, is developed by several students. Being presented by a team or individually such a project gets practical significance and serves as a response to a specific request from a regional enterprise. At the same time, professors and employers have the opportunity to assess the level of readiness of the graduate for independent professional activity, the formation of their competence established by the federal state educational standards.

The introduction of modern digital technologies in various spheres of life and industrial activities requires a qualitatively new approach to the planning and development of the final qualification work. The participation in this program of students working in a team allowed us to show the relationship between the spheres of professional activity, actualized the need for studying both the disciplines of the professional cycle and the cycle of "Informatics. The Information Technology".

The professors should pay special attention to the content of the electronic resources selected for study. The expertise of electronic resources includes several aspects: technical expertise; design-ergonomics expertise; content expertise. With all the abundance of information that students receive and process, it is necessary to monitor the quality and reliability of the data presented. The materials must correspond to the subject area in accordance with the federal state educational standards as well as meet the standards of the modern Russian language. The availability, completeness and relevance of the knowledge presented in the content should correspond to the level and profile of the university training. Besides, the important aspects should be the elimination of unreliable, pseudoscientific facts; compliance of the content of the resource with the goals and objectives of spiritual and moral development and education of a personality as the citizen of Russia.

The "Russian Electronic School" project is an example of implementation of the innovative training, a structural element of the Russian government program "The Development of Education for the years 2013-2020'. The web portal includes interactive lessons on academic subjects. At the same time, compliance with the federal state educational standards is a prerequisite. The best practices of the best teachers in Russia are presented here in open access for students. The next example of the Russian educational projects is the "Moscow Electronic School". This service as an example of a progressive use of modern digital technologies, allows us to apply innovative approaches to the educational process.

Thus, one of the ways of improving informational training is the competent use of distant learning systems (DLS). The analysis showed that the implementation of the opportunities of the DLS makes it possible to significantly facilitate the work of teachers and bring it to a qualitatively new level. Providing each discipline with a full and complete distant course within the DLS allows the students to get access to the materials of the 
disciplines, on the one hand, and on the other hand, it provides an opportunity to control the activity of students, regulate the content and forms of training if necessary, and automate the assessment of the academic performance.

The joint use of services such as ZOOM, Microsoft Teams, and e-mail along with the DSL allows improving the process of remote interaction of participants in the educational process. The training sessions can be conducted in the format of video conferences, with invitations and notifications about the beginning of the meeting being distributed within the team via email and the calendar. Sending files, sharing remote applications, recording video conferences automatically on a network disk for one or more teams results in fast exchange of information of various types, repeated return to the material if necessary, keeping records and controlling educational and methodological activities of the participants of the educational process of the university. At the same time, it is worth noting that the implementation of the opportunities of these services is necessary not only for remote training. Modern realities require fast work with large amounts of information of various types, which is unrealistic without the use of modern information technologies. The implementation of the opportunities of the above listed software products allows distributing the learning time of students in a most flexible way, conduction an individual and differentiated approach, taking into account the requirements of the competence model.

One more way of improving the informational training of students is the use of online software for collaborative work. Modern projects for the development of economy and education require, first of all, a teamwork, that is, future specialists should be able to use the software for collective work in various areas of their professional activity. Fax machines and e-mail no longer cover the needs of modern business activities. The ability to use software tools for working with files on the network, joint editing of documents of various formats have become the mandatory skill of informational training of a specialist. First of all, these are services such as the Microsoft Office 365 package, applications Draft, Penflip, Authorea, Canva, Google, and others. This is considered in more detail in the work of Ivanova D.S. [12]. Students were taught this within the framework of the disciplines "Information communication technologies and media information literacy", "Information technologies in professional activities"

Innovations in the modernization of informational training of future specialists are determined by the requirements of the Russian federal project "Artificial Intelligence". Almost all spheres of human activity are undergoing qualitative changes, which are caused by 'the civilization of the economy'. In particular, the study of artificial intelligence is included in the school curriculum in Russia, which cannot help influencing the educational programs of the university.

Subject teachers together with computer science teachers create the bases for review and analysis of software on artificial intelligence technologies in the professional field of students. The students get acquainted with innovations in their specialty that appear during the period of university education, and apply the possibilities of modern digital technologies in practice. Artificial intelligence provides the opportunity to obtain data from a variety of sources, use predictive analytics and machine learning, enables collaborative and personal learning.

In the process of the research, we observe not only the acquisition of knowledge, skills and abilities, but also the development of such personal qualities as thinking, independence, self-education, creativity, and cognitive interest as well as formation of emotional, aesthetic and initiative side of the trainees. The project-based method allows students to identify and formulate professional tasks, find ways to solve them, work with the digital resources of their specialization and adapt to new conditions.

After carrying out the work with the students of the experimental group in the directions of development of their information training presented above, repeated testing of the 
students of both groups was carried out in order to determine the effectiveness of the work carried out. Analysis of the data obtained using the methodology of Bespalko V.P., showed changes in the level of information training of all students.

In the experimental group, at the ascertaining stage, the 1 st adaptive level was demonstrated by the majority of students, and at the control group - only $8 \%$ of them. After carrying out purposeful developmental work, the number of students with a presentation level slightly increased, and with an integrative level - increased more than 6 times (Table 2).

Table 2. The level of informational training of students of the experimental group at the ascertaining and control stages

\begin{tabular}{|c|c|c|}
\hline Level & \multicolumn{2}{|c|}{ Number of students (in\%) } \\
\hline & Ascertaining stage & Control stage \\
\hline Adaptive & 70 & 8 \\
\hline Presentational & 20 & 30 \\
\hline Integrative & 10 & 62 \\
\hline
\end{tabular}

The control group students who were trained in information technology using the traditional method also showed positive dynamics in the level of information training. If at the ascertaining stage the 1st adaptive level was found in more than half $(68 \%)$ of the students, then at the control stage - only in $7 \%$ of them; the number of students with the 2nd presentation level increased more than 2 times (from 21 to 55\%), and the number of students with the integrative level increased more than 3 times (Table 3).

Table 3. The level of informational training of students of the control group at the ascertaining and control stages

\begin{tabular}{|c|c|c|}
\hline Level & \multicolumn{2}{|c|}{ Number of students (in\%) } \\
\hline & Ascertaining stage & Control stage \\
\hline Adaptive & 68 & 7 \\
\hline Presentational & 21 & 55 \\
\hline Integrative & 111 & 37 \\
\hline
\end{tabular}

At the same time, at the control stage, the integrative level of information training among students of the experimental group was significantly higher than among students of the control group (Table 4).

Table 4. The level of informational training of students of the experimental and control groups at the control stage

\begin{tabular}{|c|c|c|}
\hline Level & \multicolumn{2}{|c|}{ Number of students (in\%) } \\
\hline & Experimental group & Control groups \\
\hline Adaptive & 8 & 7 \\
\hline Presentational & 30 & 55 \\
\hline Integrative & 62 & 37 \\
\hline
\end{tabular}

The conclusion about the reliability of the obtained results was made on the basis of statistical processing. As the experimental data there were the samples made up of the points of the control and experimental groups before and after training. The nonparametric criteria of Wilcoxon, Fisher - Yates, and McNamara were used as a criterion for evaluating the reliability of a positive shift. After completing the training, the analysis of the test results showed a shift in the levels of informational training in the control and experimental 
groups. The results obtained indicate a significant difference between the initial and final levels of informational training of the students.

However, the analysis of the projects completed by the students and the qualitative analysis of the responses of the trainees from the both groups to the questions of questionnaires and tests showed that the students of the experimental group showed a higher level of readiness for self-study, self-education and self-upbringing.

The effectiveness of this observation must be proved by statistical methods. The value of shifts in the level of informational training in the control and experimental groups was estimated using the multifunctional Fisher - Yates test. The value of the positive shift in the level of informational literacy in the experimental group exceeds the value of the positive shift in the informational literacy in the control group (the empirical value of the FisherYeetis test 1.85; significance level 0.012).

The analysis of educational activities showed that the implementation of the proposed approach of the project method based on modern digital technologies significantly increases the motivation for professional training. At the same time, each student has the opportunity to choose their own level of difficulty and the pace of the task, to determine the theme of interest to them. It is worth noting the development of students' independence in the experimental groups, the growth of their creative activity and, as a result, the increase in the effectiveness of the learning process.

Therefore, it can be stated with a sufficient level of confidence that the proposed methodology effectively affects the process of improving the informational training of future specialists, which indicates the correctness of the chosen training methods.

\section{Discussion}

Analyzing the quantitative and qualitative results obtained during the experiment, we can conclude that the methods of projects based on network software, distant education systems, and artificial intelligence systems in professional activities allow us to deeply individualize and differentiate the educational process.

This is due to the fact that the theme, scenario, course and pace of work are chosen by each student individually and meet the modern requirements of informational interaction, personal needs, inclinations and professional orientation of students, it is also possible to work in micro groups of 2 to 5 people. Working on projects while studying at the university, the students choose a relevant theme for their professional subject, taking into account the time and plan of practical training in their field, and have the opportunity to practically assess the received projects.

The involvement of the university, the region, and the Russian Federation in the project activities allows the future young specialists to understand the importance of their profession while at the university, to contribute to the improvement of the economic situation, and the field of activity chosen by them.

In addition, students actively use the project-based approach in solving extracurricular problems, they develop special projects for the youth in various areas - interethnic relations, science, culture and art, sports, youth interaction, intellectual development, volunteer movement, and many others. All these areas are important for the comprehensive development of young people. They require systematic approach to implementation, as well as contribute to student patriotic education.

Thus, the project-based method of training, monitoring and control of the content of electronic resources, the integrated use of distant learning systems, online software for collaborative work, and application of artificial intelligence technology in education will help to form the media literacy of future specialists that meets the modern requirements of the economy and society. 
Working on such projects, future specialists have a specific goal to apply the acquired knowledge in practice, whereas with traditional forms of training such motivation is much lower. When working in the experimental group, the acts of a student, as shown by observations, are characterized by the activation of such personality traits as thinking, independence, creativity and cognitive interest. In addition, we should also highlight such important factors as the removal of psychological barriers of fear of computer technology and digital technologies in general, as well as the refusal of the belief that the use of information and communication technologies plays an inconsiderable role in professional activities. The introduction of the results of students' own creativity into the real process contributes to the formation of professionalism, and improves patriotic education.

The development of the level of independence and cognitive interest was observed during tests with the use of various methods, during which students answered questions from questionnaires. On the basis of psychodiagnostics: conversations, observations, testing - the students' personal abilities were revealed. The analysis of the results of psychodiagnostics, firstly, allowed us to draw a conclusion about the effectiveness of the selected forms and methods of innovative areas of informational training, and secondly, contributed to the division of trainees into microgroups according to the level of complexity of tasks. The most capable students, in addition to solving their tasks, acted as consultants and experts in the group, which contributed to the intensification of the educational process.

The observations of the experimental group students showed that during the implementation of projects, students' knowledge in the field of digital technologies was expanded. In addition, there was removed the fixation on and addiction to the formal research methods and solving only typical tasks. At the same time, the share of independent work of students was growing due to the fact that each student created their own individual project. The additional hardware and software were selected and applied in the educational process by the students themselves. Trainees had the opportunity to use the Internet resources, various training databases, ready-made professional software packages, etc. The positive side was the acquisition of methodological skills in the use of various means of modern information technologies.

During the experiment, it was noted that the students of the experimental group actively participated in student scientific and practical conferences, showed a higher level of readiness for practical training, independence and creativity in fulfilment of their course and diploma projects. They carried out the orders obtained from the faculty, university, and enterprises for the development of various software products independently or in collaboration with professors or programmers. The work resulted in a positive emotional response from the authors themselves, as well as other students, employees of the university and enterprises. This contributed to the activation of educational interaction between students and professors.

Improving the effectiveness of the educational process had a positive impact on the emotional state of future specialists, as well as increased their readiness for further professional activity.

\section{Conclusions}

Thus, the analysis of the experience of the proposed approach to the informational training at the university, as well as the analysis of the results of the pedagogical experiment to determine the effectiveness of the project-based methodology of informational training allows us to draw the following conclusions.

Implementation of innovative approaches to the informational training of university students, based on the use of the project method on modern digital technologies: network software, distant education systems, artificial intelligence technologies, contributes to the 
formation of the competence in the field of professional activity and information interaction;

As a result of improving the informational training, the students experienced the removal of psychological barriers and fixations, as well as formed informational culture, practical and methodological skills and capabilities, perfected their knowledge of setting and solving problems, formed readiness to carry out experimental researches. They developed their independence, creativity, communicative, organizational, and intellectual abilities, and formed an emotionally positive view to the educational process and future professional activity;

Modern realities have shown the need for mastering new knowledge, acquiring skills and abilities, have updated the study of the "Informatics" cycle, showed inter-subject links with the disciplines of the professional cycle in all areas of study. At the same time, the task of professors is to quickly respond to new challenges of life, to encourage students by their personal example to improve the quality of professional training, and develop the global competitiveness of Russian education on the basis of IT infrastructure.

The result of improving informational training is an increase in the share of independent, creative work of students; modernization of the content of the academic disciplines in accordance with modern requirements; participants' involvement in the educational process with project activities at the university, and in the regional and allRussia level; the ability to build up an individual way of training and work; improvement of the competitiveness of Russian professionals in various fields according to the "Digital Economy of Russia" national program and the federal project "Artificial Intelligence" in Russia.

\section{References}

1. G. Karhanyan, G. Cross, Cultural Studies: Education and Science 5 (2), 92-96 (2020).

2. T. Gounko, W. Smale, Compare: A Journal of Comparative and International Education 37 (4), 533-548 (2009). DOI: 10.1080/03057920701366358

3. E. Ferlie, C. Musselin, G. Andresani, Higher Education 56 (3), 325-348 (2008). DOI: 10.1007/s10734-008-9125-5

4. Z.I. Ivanova, N.V. Danilina, M.A. Slepnev, Journal of Applied Exercise Physiology 8 (2.1), 1003-1009 (2019).

5. S. Grek, J. Ozga, Public Policy and Administration 25 (3), 271-288 (2010). DOI: 10.1177/0952076709356870

6. G. Gurova, N. Piattoeva, T. Takala, European Education 47 (4), 346-364 (2015).

7. T.I. Vlasova, New media today: the development of theories (2015).

8. T.V. Shagdarova, S.N. Pavlova, Science and Technology 1, 99-109 (2020).

9. P. Guo, N. Saab, L.S. Post, W. Admiraal, International Journal of Educational Research 102 (2020)

10. O.V. Yakovleva, Bulletin of the Russian State Pedagogical University. A.I. Herzen, (2006) 216-219.

11. Yu.A. Yuzhakova, D.S. Ivanova, V.A. Lavrentev, M.V. Somova, Russian linguistic Bulletin 4 (24), 67-70 (2020)

12. D.S. Ivanova, O.V. Knyazkova, M.V. Somova, Psychological and pedagogical Search 1 (57), 7-15 (2021). DOI: 10.37724 / RSU.2021.57.1.006. 